\title{
Study of adverse drug reactions and clinical profile of elderly in relation to polypharmacy
}

\author{
Nagaraja B S', Keerthana Sharma² \\ ${ }^{1}$ Professor and Head, Department of General Medicine, Bangalore Medical College and Research Institute, KR Road, \\ Bangalore, ${ }^{2}$ Under Graduate Student, Bangalore Medical College and Research Institute, K R Road, Bangalore
}

Background: Polypharmacy is a becoming more prevalent in older adults and adverse risk increases with age-related change. Adverse drug reactions (ADRs) are common in older adults and worrisome aspect of treatment in elderly. Aims and Objective: The study aimed to identify the common clinical conditions leading to polypharmacy and to compare the adverse drug profiles of the 2 groups. Materials and Methods: This case-control study was conducted in Hospitals attached to BMCRI, where 200 patients aged 65 or more were interviewed. 100 elderly patients using 5 or more drugs were identified as cases and assessed against a control group of 100 patients. Results: Our study found that ADRs were found to be three times higher in individuals on polypharmacy compared to the control group (OR $3.467595 \%$ $\mathrm{Cl} 1.6241$ to 7.4035$)$. The most commonly occurring ADRs were dyspepsia (OR 1.9259), drowsiness (OR 3.5926) and fatigue (OR 1.5319) with increased incidence in the case group. The most common conditions associated with polypharmacy were found to be hypertension (53\%), diabetes mellitus(46\%), COPD (14\%) and IHD(14\%). $66 \%$ of the study group had two or more of the above diseases, whereas in the control group only $32 \%$ had multiple illnesses. The most commonly prescribed medications were antihypertensives $(61 \%)$, hypolipidemics $(44 \%)$, antiplatelets $(41 \%)$ and antibiotics $(40 \%)$. Conclusion: Polypharmacy in the elderly comes with a significant increase in adverse effects. The reduced pill burden will not only decrease ADRs and improve compliance, but will also result in greater patient satisfaction and mental health, thereby improving the quality of geriatric care.

Access this article online

Website:

http://nepjol.info/index.php/AJMS

DOI: 10.3126/ajms.v10i6.22757

E-ISSN: 2091-0576

P-ISSN: 2467-9100

Key words: Adverse drug reactions (ADR); Clinical profile; Elderly; Polypharmacy

\section{INTRODUCTION}

Polypharmacy refers to the use of excessive or multiple medications by a patient, defined broadly by the WHO as "the administration of many drugs at the same time or the administration of an excessive number of drugs."

There is no standard cut point with regard to the number of medications that is agreed upon for the definition of polypharmacy. But taking five or more drugs is generally agreed upon to be on polypharmacy, as studies have shown that the incidence of adverse drug reactions (ADR) significantly increases beyond this number. ${ }^{2}$

An alternative definition for polypharmacy is the use of more medications than are medically necessary. ${ }^{3}$
Beer's criteria become useful when classifying a drug as inappropriate in the elderly, and updated consensus guidelines of this criteria has served as a guide to choosing the ADRs of special importance in this study. ${ }^{4}$

Polypharmacy is more common in the geriatric population as they suffer from multiple co-morbidities like diabetes, hypertension, coronary artery disease, cancer and a multitude of complications including but not limited to incontinence, instability, impaired intellect and immobility. This is also the age group most significantly affected by polypharmacy due to impaired hepatic and renal clearance of drugs, and higher risk of overdosing due to failing memory. For the same reasons, polypharmacy in the elderly is associated with higher incidence of adverse drug reactions, drug interactions, 
ADR related hospitalization, and decreased compliance and increased expenditure. ${ }^{5-7}$

According to the census of India, the percentage of elderly population has gone up from 6 to 8 percent of the total population from 1991 to $2011 .{ }^{8}$ In 2015, life expectancy at birth was 68.3 years in India; 66.9 years for men and 69.9 for women, according to the WHO's World Statistics Report 2017.?

The effects of polypharmacy, especially in the elderly, have been less studied in a developing country like India. ${ }^{10}$ This study focuses on identifying the adverse drug reactions associated with polypharmacy and the clinical conditions that are associated with it in our neighborhoods.

\section{Aims and objectives}

To identify the conditions that are most commonly associated with polypharmacy in the elderly and comparatively assess the adverse drug profile of the patients using polypharmacy versus others not using it.

\section{Study design and methodology}

This is a case-control retrospective study of the elderly, defined as those individuals above 65 years of age. The study population consisted of 200 patients, who were randomly selected from the departments of general medicine and allied individuals (cardiology, nephrology, casualty, neurology) of Victoria Hospital, Bowring and Lady Curzon Hospital, Bengaluru. Duration of the study was between September and October 2016. Patients aged $\geq 65$ years with the informed consent signed were included in the study. Age less than 65 years and not taking any medications, Patients not giving voluntary informed and patients with altered sensorium, severely debilitated condition, dementia and other illnesses with cognitive impairment and mental retardation were excluded from the study. The results were analysed using descriptive statistics. Odd ratios with confidence intervals and percentages were used to describe the results wherever applicable. $\mathrm{p}=$ the event of success PK $(0.60) \mathrm{Q}=$ The event of failure (1-0.60) $=0.40(0.005)$.

\section{Defining case and control groups}

All patients who concurrently consumed five or more drugs per day, for any length of time, were identified as on polypharmacy, 100 of these were chosen to constitute the case group. 100 elderly patients who consumed less than five drugs at a time but consumed at least one medically indicated drug, acted as the control group.

Elderly patients attending OPD or admitted in the wards of the mentioned departments were selected randomly, and sorted into case or control groups. Consent was obtained.
Demographic data were obtained. They were interviewed and examined to assess the following;

In patients taking more than or equal to five drugs, the different conditions for which these drugs were prescribed was recorded. The association of polypharmacy with different diseases was thus charted. The relative incidence of adverse effects in the two groups, case vs. control groups, was compared according to the odds ratio for the specific adverse effect. In this regard, special importance was given to the following ADRs;

- ADR related hospitalization

- Falls

- Delirium

- Urinary retention or incontinence

These ADRs comply with Beer's criteria for inappropriate use of medications in the elderly. All the drugs the patients in both groups were currently consuming were recorded, along with the duration and dosage. This was used to identify the drugs most commonly associated with polypharmacy. Any correlation between duration of polypharmacy and ADR incidence was looked for.

\section{RESULTS}

Among the patients interviewed in the case group, 54\% were males and $46 \%$ were females while in the control group, $50 \%$ of the patients were male and $50 \%$ were female.

Comparative assessment of incidence of adverse drug reactions in case vs. control groups

The incidence of adverse drug reactions was found to be three times higher in individuals on polypharmacy compared to the control group (OR 3.4675 95\% CI 1.6241 to 7.4035).

The most commonly occurring adverse drug reactions were dyspepsia (OR 1.9259), drowsiness (OR 3.5926), fatigue (OR 1.5319) and loss of appetite (OR 2.5789), with increased incidence in the case group (Table 1).

\section{Clinical conditions associated with Polypharmacy}

The most common clinical conditions associated with polypharmacy were found to be hypertension $(53 \%)$, diabetes mellitus (46\%), COPD(14\%), $\operatorname{IHD}(14 \%)$, infectious disorders $(16 \%)$ and CVA $(18 \%)$ (Table 2 and Graph 1). It was found that presence of multiple co-existing diseases showed increased correlation with polypharmacy. Sixty six percent of the study group had two or more of the above mentioned diseases, whereas in the control group only $32 \%$ had multiple illnesses.

\section{Commonly prescribed drugs in the case group}

Fifty four different types of drugs were consumed in the case group. Antihypertensives (61\%), hypolipidemics (44\%), 


\begin{tabular}{|c|c|c|c|c|}
\hline & Adverse drug reaction & $\mathrm{N}=$ study group $(\%)$ & $\mathrm{N}=$ control group $(\%)$ & Odds ratio with confidence interval \\
\hline 1. & ADR related hospitalization & 2 & 1 & 2.0204 (0.1803 to 22.6462$)$ \\
\hline 2. & Falls & 6 & 3 & $2.0638(0.5015$ to 8.4929$)$ \\
\hline 3. & Delirium & 2 & 1 & 2.0204 (0.1803 to 22.6462$)$ \\
\hline 4. & Urinary retention/incontinence & 5 & 2 & $2.5789(0.4884$ to 13.6173$)$ \\
\hline 5. & Presence of any ADR & 30 & $11 \%$ & 3.4675 (1.6241 to 7.4035$)$ \\
\hline
\end{tabular}

\section{Table 2: Conditions encountered in the case group and the fraction of individuals suffering from them}

\begin{tabular}{llc} 
& Clinical conditions & Percentage of individuals on Polypharmacy (\%) \\
1. & Hypertension & 53 \\
2. & Diabetes Mellitus & 46 \\
3. & Chronic obstructive pulmonary disease & 14 \\
4. & Ischemic heart disease & 14 \\
5. & Cerebrovascular accident & 18 \\
6. & Infections & 16 \\
7. & Chronic Kidney disease & 8 \\
8. & Left ventricular failure/congestive cardiac failure & 7 \\
9. & Neuropathy & 4 \\
10. & Nephrolithiasis & 4 \\
11. & Acute kidney injury & 3 \\
12. & Benign prostatic hypertrophy & 2 \\
13. & Cirrhosis & 2 \\
\hline
\end{tabular}

\begin{tabular}{|c|c|c|}
\hline $\begin{array}{l}\text { Duration of } \\
\text { polypharmacy }\end{array}$ & $\begin{array}{c}\mathrm{N}=\text { case group } \\
(\%)\end{array}$ & $\begin{array}{c}\% \text { of } \mathbf{N} \\
\text { experiencing ADRs }\end{array}$ \\
\hline$<1 \mathrm{~m}$ & 61 & 16 \\
\hline $1 m-3 m$ & 13 & 25 \\
\hline $3 m-6 m$ & 3 & 66 \\
\hline $6 m-2 y$ & 6 & 100 \\
\hline $2 y-5 y$ & 17 & 47 \\
\hline
\end{tabular}

antiplatelets (41\%), antibiotics $(40 \%)$ and hypoglycemic $(33 \%)$ emerged as the biggest classes of drugs, with more than $40 \%$ of the study group consuming any one of them. The most commonly prescribed drugs i.e, consumed by more than $15 \%$ of the study group include atorvastatin (44\%), carvedilol $(29 \%)$, telmisartan $(25 \%)$, frusemide $(18 \%)$, metformin $(20 \%)$, gliclazide $(16 \%)$, aspirin $(35 \%)$, Duolin-salbutamol + ipratropium bromide $(18 \%)$, ceftriaxone $(22 \%)$ and ranitidine $(22 \%)$.

Correlation between duration of polypharmacy and incidence of ADRs

It was found that the frequency of ADRs increases significantly when the patient has been on polypharmacy for 3 months or more, and thereafter varies between 100\% and $47 \%$ in the other groups (Table 3 and Graph 2).

\section{DISCUSSION}

Polypharmacy and adverse drug reactions

Our results are similar to studies by Bourgeois et al. ${ }^{11}$ where outpatients taking 5 or more medications had an
$88 \%$ increased risk of experiencing an ADR compared to controls and by Marcum ZA et $\mathrm{al}^{12}$ where a patient taking more than 5 medications was almost 4 times as likely to be hospitalized from ADR. The three-fold increase in incidence of ADRs seen in the geriatric population can be attributed to several factors;

- Increased sensitivity to drug action in the elderly for any individual drug, as shown by the increased odds ratio of developing an ADR compared to the general population. ${ }^{13}$

- Lack of patient awareness and follow up, especially in rural settings (from which much of our study population hails. ${ }^{14}$

- Inadequate patient-physician interaction. ${ }^{15}$

Common clinical conditions and drugs encountered Most of the patients on polypharmacy suffered from at least one of these conditions: hypertension, diabetes mellitus, COPD, IHD, infectious disorders and CVA.

- The largest fraction of patients were hypertensives $(53 \%)$ and patients with diabetes $(46 \%)$. The use of polypharmacy in them can be easily attributed to the various classes of drugs prescribed in these conditions, which are aimed at preventing both micro- and macrovascular complications, and halting the progression of those that have already occurred.

Duration of polypharmacy and its consequences

Our study showed that a majority of patients on polypharmacy $(61 \%)$ have been using it for less than 1 month. This is a healthy finding, as studies have shown that long-term polypharmacy is more problematic than if 


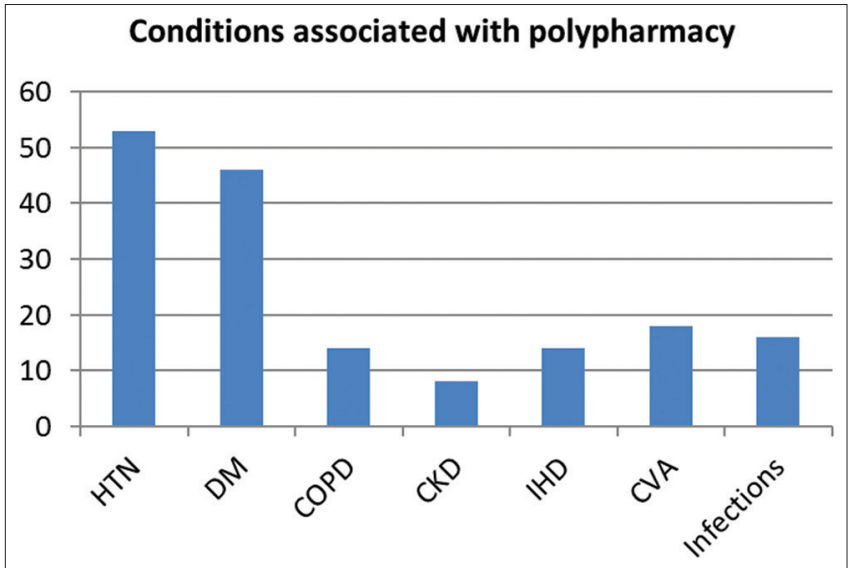

Graph 1: Graph showing percentage of patients with different clinical conditions that are on polypharmacy

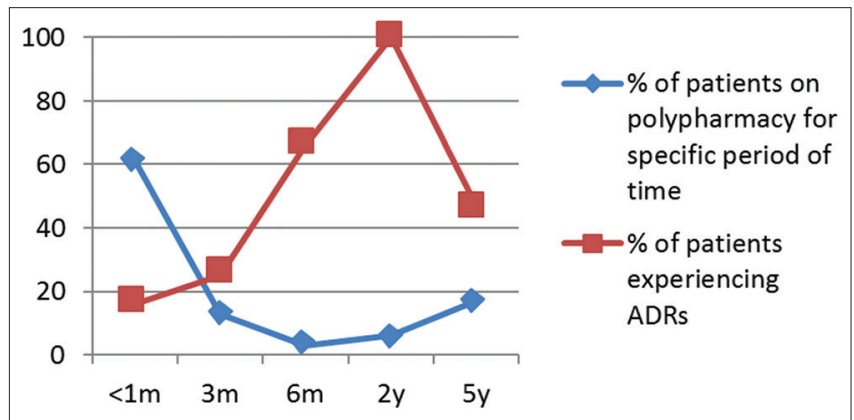

Graph 2: Line chart showing correlation between duration of polypharmacy and incidence of ADRs

the patient has been on it for only a short term. ${ }^{7}$ Accordingly, our study also showed that the percentage of individuals in the case group experiencing an ADR increased with the duration of polypharmacy; $16 \%-25 \%$ when used for less than 3 months, but increasing to upto $100 \%$ on long-term use. However these results need to be corroborated by larger studies, as the absolute number of patients in each category was too small for statistical reliability.

\section{CONCLUSION}

Polypharmacy, even though sometimes necessary in the elderly because of multiple co-morbidities, results in an increase in adverse drug reactions in the elderly. Most commonly observed ADRs were mild and non-life threatening. However the incidence of more serious and disconcerting ADRs like hypoglycemia, falls, delirium and urinary retention/incontinence are also significantly increased in the presence of polypharmacy.

Polypharmacy and its consequences can be mitigated by the following methods ${ }^{16}$;

- Prescribing according to Beer's criteria and WHO criteria
- Periodically reviewing the prescriptions of elderly patients with multiple illnesses and discontinuing redundant medications. ${ }^{17}$

- Improving awareness among people against indiscriminate use of OTCs and the effects of polypharmacy. This leads to better reporting of polypharmacy-induced ADRs and drug-interactions

- Use of electronic medical records based intervention to identify the pattern of polypharmacy and intervene. ${ }^{18}$

\section{ACKNOWLEDGEMENT}

We sincerely thank all the individuals who have supported us for the study. We thank Mr. Pradeep BK (Biocon) for scientific assistance.

\section{REFERENCES}

1. Monégat $M$, Sermet $C$, Perronnin $M$ and Rococo $E$. Polypharmacy: definitions, measurements and stakes involved. Questions d'économie de la Santé. No. 204, December 2014.

2. Maher RL, Hanlon JT and Hajjar ER. Clinical Consequences of Polypharmacy in Elderly. Expert opinion on drug safety 2014; 13 (1):10.1517/14740338.2013.827660.

3. Tjia J, Velten SJ, Parsons C, Valluri S and Briesacher BA. Studies to reduce unnecessary medication use in frail older adults: a systematic review. Drugs Aging 2013;30:285-307.

4. Fick DM, Cooper JW, Wade WE, Walter JR and Beer MH. Updating the Beer's criteria for potentially inappropriate medication use in older adults: results of a US consensus panel of experts. Arch Intern Med 2003; 163 (22):2716-2714.

5. Schuler J, Dückelmann C, Beindl W, Prinz E, Michalski T and Pichler M. Polypharmacy and inappropriate prescribing in elderly internal-medicine patients in Austria, Wien KlinWochenschr 2008: 120; 733-741.

6. Rollason $\mathrm{V}$ and Vogt $\mathrm{N}$. Reduction of polypharmacy in the elderly: a systematic review of the role of the pharmacist. Drugs Aging 2003;20:817-832.

7. Hovstadius $B$ and Petersson G. The impact of increasing polypharmacy on prescribed drug expenditure-a register-based study in Sweden 2005-2009. Health Policy 2013; 109:166-174.

8. 2011 Census. Government of India. http://www.censusindia.gov. in/vital_statistics/SRS_Report/9Chap\%202\%20-\%202011.pdf.

9. World health statistics 2017: monitoring health for the SDGs, Sustainable Development Goals. Geneva: World Health Organization; 2017.

10. Mohammed SS, Sreenath MK, Vishnu VG, Jose F, Siraj ST and Anand VPR. The Prevalence of Polypharmacy in South Indian Patients: A Pharmacoepidemiological Approach. Indian Journal of Pharmacy Practice 2012; 5(3): 40-44.

11. Bourgeois FT, Shannon MW, Valim C and Mandl KD. Adverse drug events in the outpatient setting: an 11-year national analysis. Pharmacoepidemiol Drug Saf 2010; 19:901-910.

12. Marcum ZA, Amuan ME, Hanlon JT, Aspinall SL, Handler SM, Ruby $\mathrm{CM}$, et al. Prevalence of unplanned hospitalizations caused by adverse drug reactions in older veterans. J Am Geriatric Soc 2012; 60:34-41.

13. Mallet $L$, Spinewine $A$ and Huang $A$. The challenge of managing 
drug interactions in elderly people. Lancet 2007; 370:185-191.

14. Ramanath K and Nedumballi S. Assessment of MedicationRelated Problems in Geriatric Patients of a Rural Tertiary Care Hospital. Journal of Young Pharmacists : JYP 2012; 4(4):273-278.

15. Fitz Gerald RJ. Medication errors: the importance of an accurate drug history. British Journal of Clinical Pharmacology 2009;67(6):671-675.
16. Monane M, Monane S and Semla T. Optimal medication use in elders: key to successful aging. In: Successful Aging. West J Med 1997; 167:233-237.

17. Weber V, White A and Mcllvried R. An Electronic Medical Record (EMR)-Based Intervention to Reduce Polypharmacy and Falls in an Ambulatory Rural Elderly Population. Journal of General Internal Medicine 2008;23(4):399-404.

\section{Authors Contribution:}

NBS- Concept and Design of the study, Manuscript preparation, Statistically analysed and interpreted, critical revision of the manuscript; KS- reviewed the literature collected data, Statistically analysed and interpreted, helped in preparing draft of manuscript.

Work attributed to:

Department of General Medicine, Hospitals attached to Bangalore Medical College and Research institute.

Orcid ID:

Dr. Nagaraja BS - (D) https://orcid.org/0000-0002-7750-697X

Keerthana Sharma - (1) https://orcid.org/0000-0002-6807-356X

Source of Support: Bangalore Medical College and Research institute, Conflict of Interest: None declared. 